\title{
Caesarean section per se does not increase the risk of offspring developing type 1 diabetes: a Swedish population-based study
}

\author{
Ulf Samuelsson $^{1}$ • Nina Lindell ${ }^{1}$ - Marie Bladh ${ }^{2}$ - Karin Åkesson ${ }^{3,4,5}$. \\ Annelie Carlsson ${ }^{6} \cdot$ Ann Josefsson ${ }^{2}$
}

Received: 18 February 2015 / Accepted: 25 June 2015 / Published online: 23 August 2015

(C) Springer-Verlag Berlin Heidelberg 2015

\begin{abstract}
Aims/hypothesis Some studies have revealed a relationship between Caesarean section (CS) and type 1 diabetes, while other studies have not. By using the Swedish paediatric quality register we investigated whether birth by CS is related to the risk of developing type 1 diabetes during childhood. Methods All children diagnosed with type 1 diabetes from 2000 to 2012 and included in the register $(n=9,376)$ were matched with four controls by year, day of birth, sex and county of birth from the Swedish Medical Birth Register.

Results Overall, $13.5 \%$ of deliveries were by CS. By group, $14.7 \%$ of children who developed type 1 diabetes were delivered by CS compared with $13.3 \%$ of control children $(p<0.001)$. Mothers with diabetes more often gave birth by CS than mothers without diabetes $(78.8 \%$ vs $12.7 \%$, $p<0.001$ ). In a logistic regression model adjusting for maternal age, maternal diabetes and BMI in early pregnancy, the
\end{abstract}

Ulf Samuelsson

ulf.samuelsson@regionostergotland.se

1 Department of Paediatrics and Department of Clinical and Experimental Medicine, Linköping University, S-581 85 Linköping, Sweden

2 Department of Obstetrics and Gynaecology and Department of Clinical and Experimental Medicine, Linköping University, Linköping, Sweden

3 Department of Paediatrics, Ryhov County Hospital, Jönköping, Sweden

4 Futurum - Academy for Health and Care, Jönköping, Sweden

5 Jönköping Academy for Improvement of Health and Welfare, Jönköping University, Jönköping, Sweden

6 Department of Clinical Sciences, Lund University, Skane University Hospital, Lund, Sweden
OR for CS was 1.0. A child who developed type 1 diabetes and had a mother with type 1 diabetes at the time of delivery had the highest OR to have been born by CS. Children of mothers without diabetes, delivered by CS, had no increased risk of developing type 1 diabetes. Maternal diabetes was the strongest predictor of childhood diabetes (OR 3.4), especially if the mother had type 1 diabetes (OR 7.54).

Conclusions/interpretation CS had no influence on the risk of type 1 diabetes during childhood or adolescence. However, maternal diabetes itself strongly increased the risk of offspring developing type 1 diabetes.

Keywords Caesarean section · Epidemiology · Pregnancy · Sex $\cdot$ Type 1 diabetes

$\begin{array}{ll}\text { Abbreviations } & \\ \text { CS } & \text { Caesarean section } \\ \text { MBR } & \begin{array}{l}\text { Medical Birth Register } \\ \text { Swedish paediatric diabetes quality } \\ \text { SWEDIABKIDS } \\ \text { register }\end{array}\end{array}$

\section{Introduction}

The incidence of type 1 diabetes in children has increased worldwide [1, 2]. In Sweden, it is the most common serious chronic disease among children under the age of 18 years. According to the Swedish paediatric diabetes quality register (SWEDIABKIDS), about 800 new cases of type 1 diabetes in children below 18 years are reported annually, and more than 8,000 children are undergoing insulin treatment [3].

Parallel to the increasing rates of type 1 diabetes an increasing Caesarean section (CS) rate has been observed [4-7] in developed countries. In Sweden, the rate of CS rose from 
$6.5 \%$ in 1974 to $17.6 \%$ in 2006 and has since stabilised at around $17 \%$ [8].

It is known that type 1 diabetes has a strong genetic component in the HLA area [9]. Environmental factors are believed to contribute to $50 \%$ of the risk of developing type 1 diabetes. Some of these factors from the perinatal period [10] are believed to increase the risk of developing the disease.

Several studies have investigated CS in relation to the risk of type 1 diabetes during childhood. The results of a meta-analysis including 16 observational studies indicated a possible association between a higher frequency of $\mathrm{CS}$ and an increased risk of type 1 diabetes [11]. Khashan et al [12], in a newly published sibling design study, show an association between elective, but not emergency, CS and type 1 diabetes. However, they also show that this association is not consistent with a causal effect, as familial confounding may account for the elevated risk.

The availability of SWEDIABKIDS and the Medical Birth Register (MBR) provides an excellent opportunity to further elucidate the potential effect of CS on the risk of childhood type 1 diabetes. It is necessary to adjust for maternal characteristics as well as for the possible differences between an elective and emergency CS.

The aim of this study was to investigate whether there is an association between CS and the risk of type 1 diabetes onset in childhood. All children who developed type 1 diabetes during the years 2000-2012 and were registered in SWEDIABKIDS were compared with a control group that consisted of children born in Sweden during the same years.

\section{Methods}

SWEDIABKIDS The quality register was stepwise and randomly introduced in Sweden during 2000-2007. Since 2008, outpatient attendance at all 43 paediatric clinics has been registered in SWEDIABKIDS. In Sweden, paediatric clinics treat all children and adolescents aged 0-18/19 years (in some cases up to 20 years of age) with diabetes from defined geographic areas. Thus, the register includes data on almost all (approximately 99\%) children and adolescents with diabetes in Sweden. In 2012, the register included data from more than 280,000 outpatient visits (annual report 2013; https:// swediabkids.ndr.nu).

Initially, up until 2007, data were registered locally by doctors and/or nurses in a specially designed programme for childhood diabetes. The register has been web-based since 2008 and is available to all paediatric diabetes centres in Sweden. SWEDIABKIDS is financially supported by the Association of Local Authorities and Regions, SALAR, which represents the governmental, professional and employer-related interests of Sweden's municipalities county councils and regions (http://english.skl.se/). SWEDIABKIDS has the status of a national quality register, and the patients are fully informed about the register before agreeing to be included.

MBR The MBR includes nearly all pregnancies that have resulted in births in Sweden since 1973 and contains information about the pregnancy, delivery and antenatal health of the child. Only $1-3 \%$ of deliveries are missing from the register each year. These cases are missing due to hospital errors in reporting. The register is based on the medical charts from antenatal, obstetric as well as neonatal care [13].

By use of the personal identification number of the women, information about height and weight in early pregnancy, parity, smoking habits, gestational week at childbirth as well as mode of childbirth was collected. In addition, information about maternal diabetes was collected which corresponded to the diagnostic code O24 in ICD-10 (International Statistical Classification of Diseases and Related Health Problems, the 10th edition). In 1997, MBR started to report the different types of diabetes; before that the diagnosis of diabetes was not further specified (i.e. diabetes could be type 1 , type 2 or gestational diabetes). In MBR, there are missing data on BMI in early pregnancy $(n=12,021)$, smoking $(n=2$, $703)$ and Apgar score $(n=7,723)$.

Study populations All patients with type 1 diabetes of $0-18 /$ 19 years of age and diagnosed between January 2000 and October 2012 and registered in SWEDIABKIDS were included $(n=9,376)$. Among these patients, 5,172 (55.2\%) were boys and 4,204 (44.8\%) were girls. The age at diagnosis varied from under 1 year of age up to 17 years of age. The children were born between 1984 and 2012; the majority (91\%) were born between 1990 and 2012. Each person included from SWEDIABKIDS was matched with four controls with the same year and day of birth, same sex and who were born in the same region of Sweden $(n=37,504)$. In this study we used information from the MBR regarding method of delivery for the total study population $(n=46,880)$. The study was approved by the Regional Ethical Review Board in Linköping (Dnr 2011/381-31) prior to any data collection.

Statistics Pearson's $\chi^{2}$ test was used to analyse the univariate relationship between mode of delivery and maternal as well as obstetric characteristics such as smoking, sex of the child, size for gestational age, birth order and proportion of children who developed type 1 diabetes. The student's $t$ test was used to assess differences between mode of delivery and continuous variables such as maternal age when giving birth, BMI in early pregnancy, birthweight and Apgar score at 5 and $10 \mathrm{~min}$. Multivariate analyses included multiple logistic regression in which the dependent variable was set to type 1 diabetes in the child and independent variables were mode of delivery, maternal diabetes, maternal age when giving birth and BMI in early pregnancy (Table 4). In addition, a separate multiple 
logistic regression model was performed in which delivery by CS was set as the dependent variable and maternal age when giving birth, BMI in early pregnancy, sex of the child and age at onset of type 1 diabetes (Table 5) were all included as independent variables. Missing data were excluded in the regression analyses. All statistical analysis was performed using IBM SPSS version 22 (IBM, Armonk, NY, USA). A $p$ value $<0.05$ (two-sided) was considered statistically significant.

\section{Results}

In Table 1, maternal characteristics and obstetric outcomes are presented. The analyses show that maternal age and BMI were higher in both the elective and acute CS groups, compared with the vaginal delivery group ( $p<0.001$; Table 1$)$.

In Fig. 1, the proportion of mothers with and without diabetes who underwent CS is shown. Delivery by CS was more common in mothers with diabetes than in mothers without diabetes: $78.8 \%(476 / 604)$ vs $12.7 \%(5,873 / 46,276)$ $(p<0.001)$.

Table 2 shows in more detail that mothers without diabetes had the same proportion of children who later developed type 1 diabetes, whether they were delivered vaginally or by CS. Mothers with diabetes had more children who later developed type 1 diabetes no matter what mode of delivery was used, and the majority of mothers with type 1 diabetes delivered by CS.
In mothers of children who developed type 1 diabetes, $14.7 \%$ gave birth by CS compared with $13.3 \%$ of mothers of children in the control group (Table $3 ; p<0.001$ ). Furthermore, $4.8 \%(n=453)$ of children who developed type 1 diabetes were delivered by acute CS compared with $3.3 \%(n=1,254)$ of controls (Table $3 ; p<0.001$ ). There was no difference between mothers with children who later developed diabetes and mothers of control children regarding planned CS $(9.9 \%$ each). However, $0.9 \%(n=328)$ of control children had a mother with diabetes compared with $2.9 \%(n=276)$ of children who later developed type 1 diabetes $(p<0.001)$. In addition, we also know that 213 of the 604 mothers with diabetes had type 1 diabetes; of these, 73 were mothers to control children $(0.4 \%)$ and 140 were mothers $(3.2 \%)$ to children who later developed diabetes (Table $3 ; p<0.001)$. Overall, and in both groups, mothers diagnosed with diabetes had significantly higher BMI in early pregnancy compared with mothers who did not have diabetes (Table $3 ; p<0.001$ ).

Unexpectedly, for children of mothers with type 1 diabetes, we observed a higher degree of development of type 1 diabetes among girls than boys $(3.5 \%$ vs $3.0 \%)$. Adding mothers with all types of diabetes made the figures more equal: $3.1 \%$ for girls and $2.8 \%$ for boys.

In the extended analyses of type 1 diabetes cases and four matched controls per case of the relationship between the development of diabetes among the children and the presence of maternal diabetes, it was found that boys more often

Table 1 Maternal characteristics and obstetric outcomes

\begin{tabular}{|c|c|c|c|c|}
\hline Maternal characteristics and obstetric outcomes & $\begin{array}{l}\text { All deliveries }(n=46,880) \\
n(\%)\end{array}$ & $\begin{array}{l}\text { Vaginal }(n=40,529) \\
n(\%)\end{array}$ & $\begin{array}{l}\text { Elective CS }(n=1,707) \\
n(\%)\end{array}$ & $\begin{array}{l}\text { Acute CS }(n=4,644) \\
n(\%)\end{array}$ \\
\hline Nonsmokers in early pregnancy & $44,177(94.2)$ & $38,260(94.4)$ & $1,590(93.1)$ & $4,327(93.2)$ \\
\hline Maternal diabetes & $604(1.3)$ & $126(0.3)^{* * *}$ & $304(17.8)^{* * *, \dagger \dagger}$ & $174(3.7) * * *, \dagger \dagger$ \\
\hline Maternal age (mean \pm SD) & $29.1 \pm 5.1$ & $28.9 \pm 5 * * *$ & $31.4 \pm 5.1 * * *$ & $30.4 \pm 5.2 * * *$ \\
\hline BMI in early pregnancy (mean \pm SD) & $23.9 \pm 4.1$ & $23.7 \pm 4 * * *$ & $24.9 \pm 4.7 * * *$ & $24.9 \pm 4.6^{* * *}$ \\
\hline \multicolumn{5}{|l|}{ Obstetric outcomes } \\
\hline Boys & $25,860(55.2)$ & $22,346(55.1)^{* * *}$ & $861(50.4)^{* * *, \dagger \dagger}$ & $2,653(57.1) * * *, \dagger \dagger$ \\
\hline Twins & $552(1.2)$ & $6(0.01)$ & $370(21.7)$ & $175(3.8)$ \\
\hline LGA & $1,728(3.7)$ & $1,327(3.3)^{* * *}$ & $141(8.3)^{* * *, \dagger \dagger \dagger}$ & $260(5.6)^{* * *, \dagger \dagger}$ \\
\hline SGA & $1,041(2.2)$ & $710(1.8)^{* * *}$ & $29(1.7)^{\dagger \dagger \dagger}$ & $302(6.5)^{* * *, \dagger \dagger \dagger}$ \\
\hline \multicolumn{5}{|l|}{ Birth order } \\
\hline 1 & $19,589(41.8)$ & $16,686(41.2)$ & $491(28.8)$ & $2,412(51.9)$ \\
\hline 2 & $17,052(36.4)$ & $14,978(37.0)$ & $702(41.1)$ & $1,372(29.5)$ \\
\hline 3 & $7,064(15.1)$ & $6,137(15.1)$ & $352(20.6)$ & $575(12.4)$ \\
\hline $4+$ & $3,175(6.8)$ & $2,728(6.7)$ & $162(9.5)$ & $285(6.1)$ \\
\hline Birthweight, g (mean \pm SD) & $3,534 \pm 581$ & $3,571 \pm 531 * * *$ & $3,300 \pm 681 * * *$ & $3,299 \pm 831^{* * *}$ \\
\hline Apgar score at $5 \min ($ mean $\pm \mathrm{SD})$ & $9.7 \pm 0.8$ & $9.8 \pm 0.7$ & $9.7 \pm 0.9$ & $9.4 \pm 1.2$ \\
\hline Apgar score at $10 \min ($ mean $\pm \mathrm{SD})$ & $9.9 \pm 0.7$ & $9.9 \pm 0.6$ & $9.9 \pm 0.7$ & $9.7 \pm 1.0$ \\
\hline
\end{tabular}

${ }^{* * *} p<0.001$ between vaginal delivery and elective CS or vaginal delivery and acute CS

${ }^{\dagger \dagger} p<0.001$ between elective CS and acute CS

LGA, large for gestational age; SGA, small for gestational age 


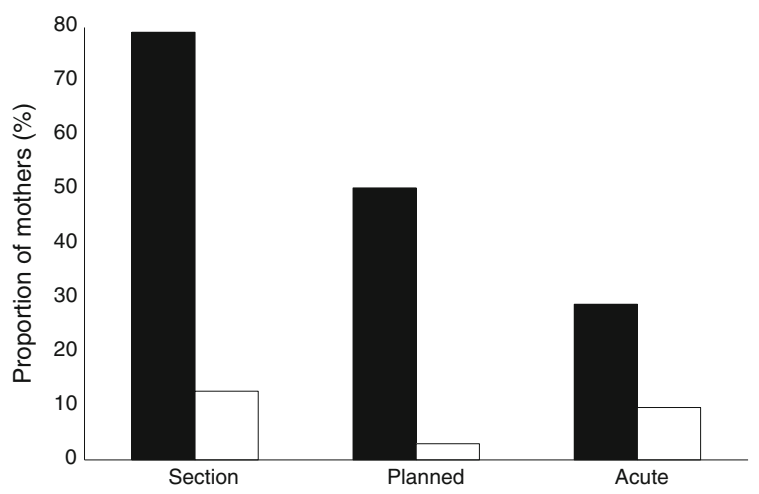

Fig. 1 A significantly higher proportion of mothers with diabetes had CS deliveries compared with mothers without diabetes. Black bars, mothers with diabetes $(n=476)$; white bars, mothers without diabetes $(n=5,873)$

developed type 1 diabetes if the mother had diabetes, compared with boys born to mothers without diabetes $(47.4 \%(144 / 304)$ vs $19.7 \%(5,028 / 25,556), p<0.001)$. The figures were about the same for girls $(44 \%$ [132/300] vs $19.7 \%$ [4,072/20,720], $p<0.001)$. When restricting our comparisons to mothers with and without type 1 diabetes this pattern was strengthened. In boys, if the mother had type 1 diabetes at the time of delivery, $61.3 \%$ (68/111) developed type 1 diabetes compared with $19.5 \%(2,182 / 11,139)$ if the mother did not have type 1 diabetes, $p<0.001$. Corresponding figures for girls were $70.6 \%$ (72/ $102)$ and $19.5 \%(1,989 / 10,203)$, respectively, $p<0.001$.

If the mother had diabetes (either type 1, type 2 or gestational), $42.1 \%(53 / 126)$ of the children delivered vaginally developed type 1 diabetes (Table 2); of those delivered with acute CS $52.3 \%$ (91/174) developed type 1 diabetes; and of those delivered by planned CS $43.4 \%$ (132/304) developed type 1 diabetes. Corresponding figures for children who developed diabetes but had mothers without diabetes were $19.7 \%(n=7,946), 18.6 \%(n=833)$ and $22.9 \%(n=321)$, respectively $(p<0.001)$. Furthermore, only including mothers with type 1 diabetes $(n=213)$ in the analysis, $97.7 \%$ of the children were found to have been delivered by CS, of which $62 \%(n=129)$ were by planned CS. In comparison, among mothers without type 1 diabetes $(n=21,342), 17.1 \%$ of children had been delivered by CS $(p<0.001)$, of which $36.3 \%$ $(n=1,323)$ were by planned CS.

Mothers of children who did not develop type 1 diabetes had about the same mean age as mothers of children who later developed type 1 diabetes: $29.02 \pm 5.1$ and $29.16 \pm 5.1$ years. However, mothers who delivered by CS were significantly older than mothers who had a vaginal delivery: $30.5 \pm 5.2$ and $28.8 \pm 5.0$ years $(p<0.001)$. Moreover, mothers who had diabetes $(n=604)$ were older than mothers without diabetes $(n=46,276): 30.55 \pm 5.2$ and $29.03 \pm 5.1$ years $(p<0.001)$. In mothers with diabetes, there were also a higher proportion of mothers who were above 30 years of age when giving birth: $58.9 \%$ compared with $45.1 \%$ of mothers without diabetes $(p<0.001)$.

The multivariate analysis In the multivariate analysis, the OR for developing type 1 diabetes, when only including CS in the logistic regression model, was estimated to be $1.12(95 \%$ CI $1.06,1.2 ; p<0.001)$, but when only including maternal diabetes the OR increased to 3.44 (95\% CI 2.92, 4.04; $p<0.001)$ and when only including maternal type 1 diabetes the OR was 7.9 (95\% CI 5.94, $10.5 ; p<0.001)$. Including both maternal diabetes and CS in the model the OR for CS was no longer statistically significant while maternal diabetes remained statistically significant (OR 2.89, 95\% CI 2.03, 4.1; $p<0.001)$. Including maternal age in the multiple logistic regression model did not alter these findings (Table 4). An interaction term between maternal diabetes and CS also did not alter these findings, as it was statistically insignificant.
Table 2 Mode of delivery: comparison between mothers to children with type 1 diabetes and mothers to control children

\begin{tabular}{|c|c|c|c|}
\hline Mode of delivery & $\begin{array}{l}\text { Control } \\
n(\%)\end{array}$ & $\begin{array}{l}\text { Children with type } 1 \text { diabetes } \\
n(\%)\end{array}$ & $\begin{array}{l}p \text { value } \\
\left(\chi^{2}\right)\end{array}$ \\
\hline All deliveries & $37,504(80.0)$ & $9,376(20.0)$ & \\
\hline \multicolumn{4}{|l|}{ Vaginal delivery } \\
\hline $\begin{array}{l}\text { Mothers without diabetes } \\
\text { Mothers with diabetes }\end{array}$ & $\begin{array}{l}32,457(80.3) \\
75(58.6)\end{array}$ & $\begin{array}{l}7,946(19.7) \\
53(41.4)\end{array}$ & 0.000 \\
\hline \multicolumn{4}{|l|}{ CS } \\
\hline $\begin{array}{l}\text { Mothers without diabetes } \\
\text { Mothers with diabetes }\end{array}$ & $\begin{array}{l}4,719(80.4) \\
253(53.2)\end{array}$ & $\begin{array}{l}1,154(19.6) \\
223(46.8)\end{array}$ & 0.000 \\
\hline \multicolumn{4}{|l|}{ Vaginal delivery } \\
\hline $\begin{array}{l}\text { Mothers without type } 1 \text { diabetes } \\
\text { Mothers with type } 1 \text { diabetes }\end{array}$ & $\begin{array}{l}14,269(80.6) \\
4(80.0)\end{array}$ & $\begin{array}{l}3,430(19.4) \\
1(20.0)\end{array}$ & 0.650 \\
\hline \multicolumn{4}{|l|}{$\mathrm{CS}$} \\
\hline $\begin{array}{l}\text { Mothers without type } 1 \text { diabetes } \\
\text { Mothers with type } 1 \text { diabetes }\end{array}$ & $\begin{array}{l}2,902(79.7) \\
69(33.2)\end{array}$ & $\begin{array}{l}741(20.3) \\
139(66.8)\end{array}$ & 0.000 \\
\hline
\end{tabular}




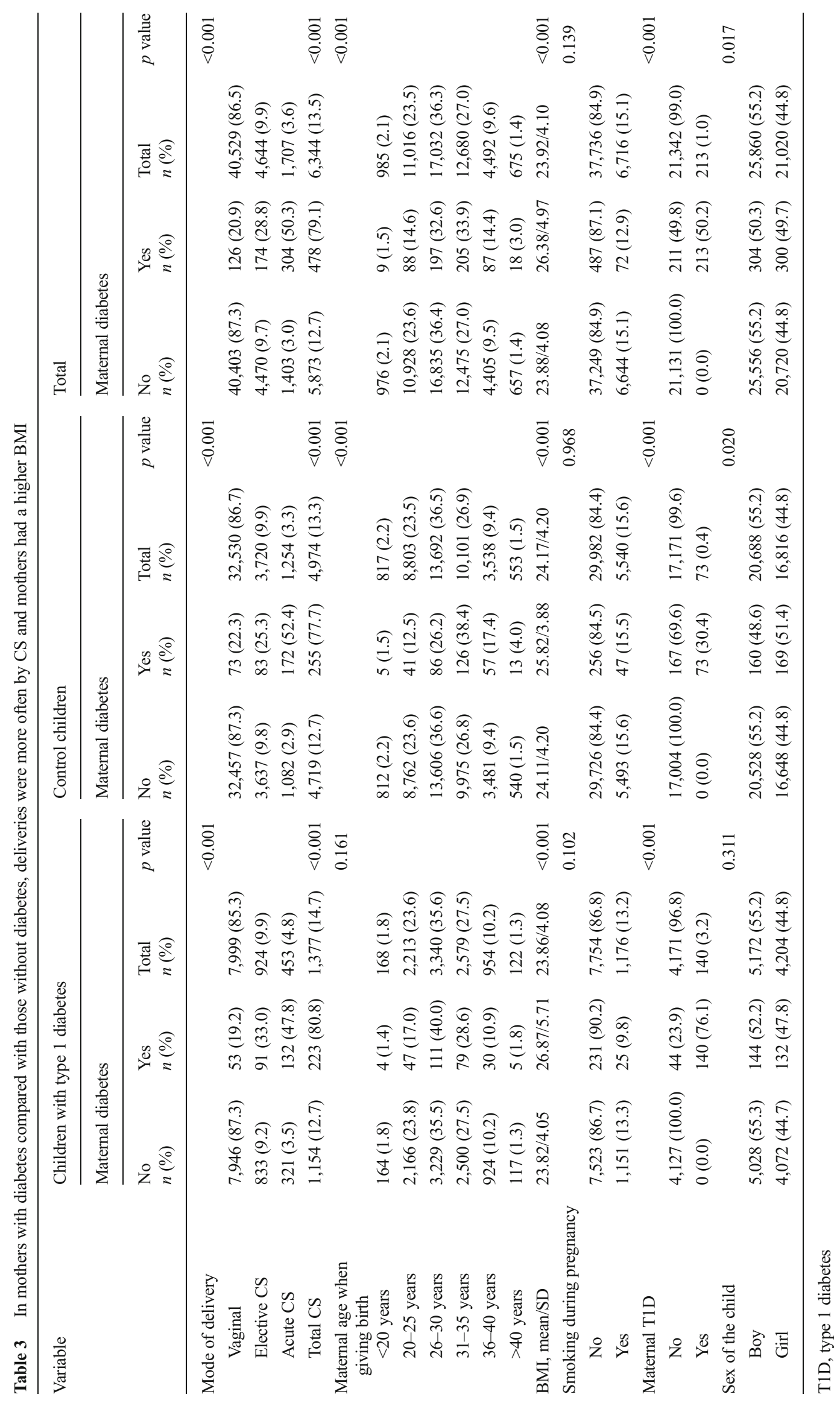


Table 4 Logistic regression model with OR for developing type 1 diabetes

\begin{tabular}{llll}
\hline Variable & Unadjusted OR $(95 \% \mathrm{CI})$ & \multicolumn{1}{l}{ Adjusted OR $(95 \% \mathrm{CI})$} & \\
\cline { 2 - 3 } & & All maternal diabetes included & Only maternal type 1 diabetes included \\
\hline $\mathrm{CS}$ & $1.12(1.1,1.2)$ & $1.02(0.94,1.10)$ & $0.97(0.88,1.07)$ \\
Maternal diabetes & $3.4(2.9,4.0)^{* *}$ & $3.4^{* *}(2.8,4.1)$ & $1.01^{* *}(1.01,1.02)$ \\
BMI in early pregnancy & $1.02^{* *}(1.01,1.02)$ & $1.02^{* *}(1.01,1.02)$ & $7.54^{* *}(5.5,10.4)$ \\
Maternal type 1 diabetes & $7.9^{* *}(5.9,10.5)$ & & $1(0.99,1.01)$ \\
Maternal age & $1(0.99,1.01)$ & $1(0.99,1.01)$ & \\
\hline
\end{tabular}

Adjusted OR includes CS, maternal diabetes and maternal age or CS, maternal type 1 diabetes and maternal age. The model only including maternal type 1 diabetes includes a total of 21,555 mothers/children. Unadjusted OR and the model for all maternal diabetes include 46,880 mothers/children. BMI and age are continuous variables

$* * p<0.01$

The diabetes population Table 5 shows the OR for CS in this population of children who later developed type 1 diabetes. For instance, when only including maternal age the OR was 1.06. If the mother had diabetes at the time of delivery the OR was 28.9. The adjusted values are nearly the same as the unadjusted ones. Hence, if a mother of a child who later developed type 1 diabetes had type 1 diabetes at the time of delivery this child had the highest likelihood of having been delivered by CS. The OR for a child who later developed type 1 diabetes to be delivered by CS if the mother had no diabetes at the time of delivery was 1.0 (95\% CI 0.93, 1.07).

\section{Discussion}

In this nationwide population-based investigation of children born from 1984 to 2012 we did not find an increased risk of diabetes during childhood and adolescence among children born by CS. Unadjusted data showed a small but significant relationship between the incidence of childhood type 1 diabetes and CS. The unadjusted OR of 1.12 was in line with the OR from other studies [11, 12, 14] but after adjustments for potential confounders, the increased risk disappeared. Our results are supported by a nationwide study from Norway that found no association between CS and the incidence of type 1 diabetes in children [15], and this has also been shown by others $[10,16]$. The effect of CS on the incidence of type 1 diabetes disappears in this study by the influence of maternal age, BMI early in pregnancy and maternal diabetes. The BMI of mothers had a small influence on the risk of type 1 diabetes in the children. As in the meta-analysis study by Cardwell et al [11] the risk of developing type 1 diabetes during childhood was very high if the mother had diabetes, especially type 1 diabetes. Consequently, the highest likelihood of a child who later develops type 1 diabetes to be delivered by CS arises if the mother has type 1 diabetes at the time of delivery.

Higher maternal age is related to an increased risk of offspring developing type 1 diabetes during childhood [11, 17, 18 ] and CS seems to be more common if the mother is above 30 years [12]. Both of these findings were verified in this study, as we found both that mothers who delivered by CS were significantly older than mothers who had a vaginal delivery and that mothers with diabetes were older than mothers without diabetes.

Table 5 Logistic regression model with the OR of delivery by CS in the diabetes population

\begin{tabular}{llll}
\hline Variable & Unadjusted OR with 95\% CI & Adjusted OR with 95\% CI & \\
\cline { 3 - 4 } & & All maternal diabetes included & Only maternal type 1 diabetes included \\
\hline Maternal age & $1.06^{* *}(1.05,1.07)$ & $1.06^{* *}(1.04,1.07)$ & $1.05^{* *}(1.03,1.07)$ \\
BMI in early pregnancy & $1.07^{* *}(1.06,1.09)$ & $1.05^{* *}(1.04,1.07)$ & $1.05^{* *}(1.03,1.07)$ \\
Maternal diabetes & $28.9^{* *}(21.3,39.3)$ & $31.2^{* *}(21.6,45.0)$ & $572 * *(79.6,4,107)$ \\
Maternal type 1 diabetes & $643.4^{* *}(89.9,4,607)$ & & $0.9(0.72,1.03)$ \\
Sex & $0.97(0.86,1.08)$ & $0.90(0.78,1.03)$ & $0.96^{* *}(0.94,0.99)$ \\
Age at onset & $0.92^{* *}(0.91,0.93)$ & $0.94^{* *}(0.92,0.95)$ & \multirow{2}{*}{. } \\
\hline
\end{tabular}

Adjusted OR includes maternal age, BMI early in pregnancy, maternal diabetes, sex and age at onset or maternal age, BMI early in pregnancy, maternal type 1 diabetes, sex and age at onset. The model with maternal type 1 diabetes includes in total 4,311 mothers/children. The model with maternal diabetes includes 9,376 mothers/children. Age and BMI are continuous variables

$* * p<0.01$ 
Warrem et al and others over the years have observed that maternal type 1 diabetes is associated with a lower risk of type 1 diabetes in the offspring than paternal type 1 diabetes [19-21]. The risk is twofold greater in children of a father than a mother with type 1 diabetes $[19,21,22]$. The reason for this finding is not known, but it could be due to differences in susceptibility genes. The intrauterine environment could be another reason. Pregnancy in mothers with type 1 diabetes is characterised by fluctuating glycaemia and altered lipid metabolism [23-25]. Unfortunately, it was not possible for us to investigate whether or not the fathers had diabetes in this study. Nevertheless, the results of this study show that hereditary factors are very strong. Irrespective of the mode of delivery, children who later developed diabetes more often had a mother with diabetes than was the case for the control children.

Over the years there have been several improvements in the treatment of diabetes, including treatment during pregnancy. Diabetic pregnancy is, therefore, perhaps less complicated now compared with 10-20 years ago. It could also be that today more women with diabetes choose to have children of their own. Perhaps the twofold greater risk of type 1 diabetes in children of a father than a mother with type 1 diabetes will disappear with time, and mothers and fathers will have the same effect on increased risk. Nevertheless, as shown by Algert et al [14], the influencing factors are most obvious in children who develop type 1 diabetes at a very young age.

Since $53 \%$ of the children and adolescents with type 1 diabetes in Sweden are boys [3], one might have expected the same pattern in this study. However, instead more girls than boys developed diabetes if the mother had diabetes, particularly type 1 diabetes. As far as we know, this finding is new but we have no explanation or answer for it.

Why is CS thought to be associated with the incidence of type 1 diabetes? One theory is that the gut microbiota may play an important role in stimulating the development of the immune system [26, 27]. Studies have shown that the gut microbiota differ in children born by CS compared with vaginally born children [28]. These differences are evident 1 day after birth and can persist for many years [29]. This difference may increase the risk of type 1 diabetes. Other theories are the hygiene hypothesis and perinatal stress. Children delivered by CS have decreased exposure to certain maternal infections compared with children born vaginally and, therefore, have an increased risk of type 1 diabetes [30]. Children born by CS often lack the stress response [31], which can result in a less mature immune system. All these theories may, of course, be particularly significant for the children who developed type 1 diabetes after CS in this study. If so, this is most obvious in the mothers with diabetes. In which case, the increased risk of type 1 diabetes is a combination of genetic and environmental factors, and these factors have their strongest impact in genetically susceptible children. Perhaps the genetic susceptibility from the mother is stronger in girls than in boys.

The major strengths of using data from national registries are the large size of collected data and the fact that populationbased information is free from recall bias. The MBR covers almost $100 \%$ of births in Sweden. The report rate is controlled every year against the births registered in the birth register at Statistics Sweden. We have no systematic dropouts as SWEDIABKIDS was stepwise and randomly introduced in Sweden between 2000 and 2007 and includes all paediatric clinics from 2008 and about $99 \%$ of all children with diabetes in Sweden. Furthermore, all diabetes teams have from the start of reporting to the register included all their patients, both current and new patients. It is possible that some underreporting of maternal diabetes could have occurred but it is probably rare. Register data can also involve misclassification problems caused by incorrect registration of diagnostic codes, and this limitation may have affected the validity of the data used in our study. If so, the incorrect registration is random and not systematic.

In conclusion, maternal diabetes at the time of delivery strongly increased the risk of diabetes in the child during childhood and adolescence. CS in itself had no obvious influence on the risk of offspring developing type 1 diabetes. Maternal diabetes, especially maternal type 1 diabetes, showed the highest risk for the child developing type 1 diabetes.

Acknowledgements We thank all paediatric diabetic teams that every year report data to SWEDIABKIDS and we also thank the staff at the maternity wards who report data to the MBR. Without these data this study would not have been possible

Funding SWEDIABKIDS is financially supported by the Association of Local Authorities and Regions, SALAR. This study was also supported by Futurum, the academy for health care, Jönköping county council.

Duality of interest The authors declare that there is no duality of interest associated with this manuscript.

Contribution statement $\mathrm{US}, \mathrm{AJ}, \mathrm{K} \AA$ and $\mathrm{AC}$ were responsible for producing the conception of the study and acquisition of data. US and MB designed and performed the statistical analyses together with NL. US and AJ wrote the first draft of the manuscript. All authors edited and reviewed the manuscript and approved the final version. The guarantor of this manuscript is US.

\section{References}

1. Diamond Project Group (2006) Incidence and trends of childhood type 1 diabetes worldwide 1990-1999. Diabet Med 23:857-866

2. Taplin CE, Craig ME, Lloyd M et al (2005) The rising incidence of childhood type 1 diabetes in New South Wales, 1990-2002. Med J Aust 183:243-246

3. Swedish paediatric diabetes quality register. Annual report 2013. Available from http://swediabkids.ndr.nu 
4. Thomas J, Paranjothy S, Royal College of Obstetricians and Gynaecologists Clinical Effectiveness Support Unit (2001) National Sentinel Caesarean Section audit report. RCOG Press, London

5. Dobson R (2001) Caesarean section rate in England and Wales hits 21\%. BMJ 323:951

6. Hamilton BE, Martin JA, Sutton PD (2004) Births: preliminary data for 2003. Natl Vital Stat Rep 53:1-18

7. Betrán AP, Merialdi M, Lauer JA et al (2007) Rates of caesarean section: analysis of global, regional and national estimates. Paediatr Perinat Epidemiol 28:98-113

8. National Board of Health and Welfare; Official statistics of Sweden (2012) Statistics - health and medical care: pregnancies, deliveries and newborn infants [in Swedish]. Available from www. socialstyrelsen.se/Lists/Artikelkatalog/Attachments/18669/2012-42.pdf, accessed 10 Aug 2015

9. Field LL (2002) Genetic linkage and association studies of type I diabetes: challenges and rewards. Diabetologia 45:21-35

10. Dahlquist GG, Patterson C, Soltesz G (1999) Perinatal risk factors for childhood type 1 diabetes in Europe. The EURODIAB Substudy 2 Study Group. Diabetes Care 22:1698-1702

11. Cardwell CR, Stene LC, Joner G et al (2008) Caesarean section is associated with an increased risk of childhood-onset type 1 diabetes mellitus: a meta-analysis of observational studies. Diabetologia 51:726-7354

12. Khashan AS, Kenny LC, Lundholm C, Kearney PM, Gong T, Almqvist C (2014) Mode of obstetrical delivery and type 1 diabetes: a sibling design study. Pediatrics 134:e806-e813

13. National Board of Health and Welfare. Report from EpC (Epidemiological centrum) [in Swedish]. Available from www. socialstyrelsen.se/lists/artikelkatalog/attachments/10961/2002112-4_20021124.pdf, accessed 10 Aug 2015

14. Algert CS, McElduff A, Morris JM, Roberts C (2009) Perinatal risk factors for early onset of type 1 diabetes in a 2000-2005 birth cohort. Diabet Med 26:1193-1197

15. Stene LC, Magnus P, Lie RT, Sovik O, Joner G, the Norwegian Childhood Diabetes Study Group (2003) No association between pre-eclampsia or caesarean section and incidence of type 1 diabetes among children: a large population-based cohort study. Pediatr Res 54:487-490

16. Bache I, Bock T, Volund A, Buschard K (1999) Previous maternal abortion, longer gestation, and younger maternal age decrease the risk of type diabetes among male offspring. Diabetes Care 22:1063-1065

17. Stene LC, Magnus P, Lie RT, Sovik O, Joner G, the Norwegian Childhood Diabetes Study Group (2001) Maternal and paternal age at delivery, birth order, and risk of childhood onset type 1 diabetes: population based cohort study. BMJ 323:1-4

18. Stene LC, Gale EAM (2013) The prenatal environment and type 1 diabetes. Diabetologia 56:1888-1897

19. Warram JH, Krolewski AS, Gottlieb MS, Kahn CR (1984) Differences in risk of insulin-dependent diabetes in offspring of diabetic mothers and diabetic fathers. NEJM 311:149-152

20. Lorenzen T, Pociot F, Stilgren L et al (1998) Predictors of IDDM recurrence risk in offspring of Danish IDDM patients. Danish IDDM Epidemiology and Genetics Group. Diabetologia 41:666-673

21. Harjutsalo V, Reunanen A, Tuomilehto J (2006) Differential transmission of type 1 diabetes from diabetic fathers and mothers to their offspring. Diabetes 55:1517-1524

22. Bonifacio E, Pflüger M, Marienfeld $\mathrm{S}$, Winkler C, Hummel M, Ziegler A-G (2008) Maternal type 1 diabetes reduces the risk of islet autoantibodies: relationships with birthweight and maternal HbA1c. Diabetologia 51:1245-1252

23. Nielsen GL, Moller M, Sorensen HAT (2006) HbA1c in early pregnancy and pregnancy outcomes: a Danish population-based cohort study of 573 pregnancies in woman with type 1 diabetes. Diabetes Care 29:2612-2616

24. Lindsay RS, Walker JD, Halsall I et al (2003) Scottish multicentre study of diabetes in pregnancy. J Clin Endocrinol Metab 88:1664-1671

25. Min Y, Lowy C, Ghebremeskel K, Thomas B, Offley-Shore B, Crawford M (2005) Unfavorable effect of type 1 and type 2 diabetes on maternal and fetal essential fatty acid status: a potential marker of fetal insulin resistance. Am J Clin Nutr 82:1162-1168

26. Gronlund MM, Lethonen OP, Eerola E, Kero P (1999) Fecal microflora in healthy infants born by different methods of delivery: permanent changes in intestinal flora after cesarean delivery. $\mathrm{J}$ Pediatr Gastroenterol 28:19-25

27. Guarner F, Malagelada JR (2003) Gut flora in health and disease. Lancet 361:512-519

28. Penders J, Thijs C, Vink C et al (2006) Factors influencing the composition of the intestinal microbiota in early infancy. Pediatrics 118:511-521

29. Salminen S, Gibson GR, McCartney AL, Isolauri E (2010) Influence of mode of delivery on gut microbiota in seven-yearold children. Gut 107:11971-11975

30. Gale EA (2002) A missing link in the hygiene hypothesis? Diabetologia 45:588-594

31. Lagercrantz H, Slotkin TA (1986) The "stress" of being born. Sci Am 254:100-107 